\title{
Female Sterilization by Tubal Ligation During C-Section in Women with a History of 2 or More C-Sections
}

\author{
Hatice KANSU CELIK ${ }^{1}$, Dilek UYGUR ${ }^{1}$, Yasemin TASCI ${ }^{1}$, Merve DURMUS ${ }^{1}$, Burcu KISA KARAKAYA ${ }^{1}$, \\ Yaprak ENGIN USTUN ${ }^{1}$
}

Ankara, Turkey

\section{ABSTRACT}

OBJECTIVE: The aim of this study is to determine bilateral tubal ligation incidence performed during $\mathrm{C}$-section in women with a history of 2 or more $\mathrm{C}$-sections and the factors affecting sterilization demand.

STUDY DESIGN: Patients who were admitted to Zekai Tahir Burak Woman's Health, Education and Research Hospital between February 2017 and June 2017 and who had a history of 2 or more C-sections between week 37 and 41 were included in this prospective cross-sectional study. These subjects were separated into 2 groups according to whether they wanted bilateral tubal ligation during C-section. Bilateral tubal ligation was performed by means of modified Pomeroy technique. Both groups were compared in terms of age, gravida, number of children living at home, education level and income status. Patients who did not want bilateral tubal ligation were asked to fill a questionnaire involving reasons for not asking for bilateral tubal ligation.

RESULTS: The number of patients who wanted bilateral tubal ligation was 51 (43\%) while those who did not want bilateral tubal ligation was 67 (57\%). Compared with patients who did not want bilateral tubal ligation, patients who wanted bilateral tubal ligation had more number of children at home and a higher number of previous C-section $(p<0.001)$. Reasons for not wanting bilateral tubal ligation consisted of religious beliefs $(26.8 \%)$, desire for protection with a reversible contraceptive method $(17.9 \%)$, partner who does not want bilateral tubal ligation (17.9\%), incompletely family size $(13.4 \%)$, respectively according to their frequency.

CONCLUSION: Bilateral tubal ligation for contraception during C-section was performed forty-three percent of women who had had a history of 2 or more C-section. In one fourth of the cases, pregnant women did not want bilateral tubal ligation due to religious beliefs.

Keywords: Female sterilization, Bilateral tubal ligation, Repeated C-section

Gynecol Obstet Reprod Med 2018;23(1):7-11

\section{Introduction}

Tubal sterilization is one of the most effective contraception methods. Female sterilization with bilateral tubal ligation

\footnotetext{
I University of Health Sciences Zekai Tahir Burak Woman's Health Education and Research Hospital Obstetrics and Gynecology, Ankara Address of Correspondence: Hatice Kansu Celik University of Health Sciences Zekai Tahir Burak Woman's Health Education and Research Hospital Obstetrics and Gynecology 06130 Ankara, Turkey h_kansu@yahoo.com

Submitted for Publication: 07.02.2017 Accepted for Publication: $\quad 09.03 .2017$
}

\begin{tabular}{|c|c|}
\hline \multicolumn{2}{|c|}{ Access this article online } \\
\hline $\begin{array}{c}\text { Quick Response Code: } \\
\text { ? }\end{array}$ & $\begin{array}{l}\text { Website: www.gorm.com.tr } \\
\text { e- mail: info@gorm.com.tr }\end{array}$ \\
\cline { 2 - 2 } & DOI:10.201613/GORM.2017.723 \\
\hline
\end{tabular}

How to cite this article: Kansu Celik H. Uygur D. Tasci Y. Durmus M. Kisa Karakaya B. Engin Ustun Y. Female Sterilization by Tubal Ligation During $C$-Section in Women with a History of 2 or More C-Sections. Gynecol Obstet Reprod Med 2018;24(1):7-11
(BTL) became popular in 1960 and it is still widely used around the worldwide for contraception purposes. It is estimated that about 180 million couples around the world choose this contraceptive method (1). On the other hand, in developing countries, use of BTL is limited due to religious prohibitions, legal limitations, inadequate opportunities, requirement of operation and the fact that the method is irreversible (2-4).

There are many methods for tubal sterilization in the literature. These methods include colpectomy, culdoscopy, laparoscopy, laparotomy and mini-laparotomy. Today, as access to fallopian tubes is easy during C-section, laparotomic BTL can be performed also on women who have completed family size $(5,6)$.

Female sterilization is generally performed during C-section in situations in which medical conditions of the mother poses danger in future pregnancies or in which fertility of the women is completed (7). Good consultancy service before operation will reduce chance of regret. This is because studies show that patients who undergo tubal sterilization during $\mathrm{C}$ section have a higher ratio of regret and some patients even 
perceive that they are forced by their doctors $(8,9)$. Most frequent reasons for regret are wanting to have a child from a new partner, death of a child or wish to have a male sex child (10). It is recommended that sterilization is conducted 6 to 12 months following birth after development of the baby is guaranteed. Meanwhile, tubal sterilization during $\mathrm{C}$-section is cost-effective (11).

Tubal sterilization is a method which is conducted during birth with $\mathrm{C}$-section and has an important role on prevention of unplanned pregnancy and reduction of maternal mortality. The aim of this study is to determine the incidence of BTL performed during $\mathrm{C}$-section in women with a history of 2 or more $\mathrm{C}$-section and the factors affecting sterilization demand.

\section{Material and Method}

This was a prospective, cross-sectional study of the patients with C-section followed by BTL at Zekai Tahir Burak Women's Health, Education and Research Hospital between February 2017 and June 2017. The study was approved by the Ethics Committee of the hospital (No: 69/2017). The clinical data of the patients were obtained from medical charts and electronic records of the hospital. Patients who did not want BTL were asked to fill a questionnaire involving reasons for not asking for BTL. Also we asked them to fill in a questionnaire involving information regarding educational and socioeconomic levels, income status, and the reasons for not wanting BTL. The criteria of inclusion were a history of at least 2 $\mathrm{C}$-sections and pregnancy of 37 to 41 weeks. Women with a history of BTL failure, underwent urgent C-section, and with pregnancies subject to fetal congenital malformations, placental invasion abnormalities, gestational diabetes, hypertension or chronic illness were excluded from the study. Patients were divided into two groups according to BTL application during $\mathrm{C}$-section. We informed patients and their husbands verbally about bilateral BTL before C-section and received written informed consent. This included information on alternative methods of long-term contraception, advantages and disadvantages as well as relative failure rates of each method.

Modified Pomeroy procedure involved clamping either of the fallopian tubes at its middle section with a pair of Babcock forceps and elevating a loop of the tube. Base of the loop of the tube was then transfixed and ligated with vicryl number 2 and the sutures held long. A 2-cm section of the tube in the ligated loop was then transected and removed with scissors. The cut ends of the tube were cleaned and inspected for any hemorrhage. The suture was cut short. A mirror procedure was performed on the contralateral tube.

Statistical analysis was carried out by using the SPSS software version 17.0 (SPSS Inc., Chicago, IL). Qualitative data were expressed as number and percentage, while quantitative data were expressed as mean and standard deviation. Sample t test and Chi-square test have evaluated associations between the categorical and continuous variables. A value of $p<0.05$ was considered statistically significant.

\section{Results}

During the study period, 119 patients with a history of 2 or more $\mathrm{C}$-section underwent $\mathrm{C}$-section. One patients were excluded from the study as BTL cannot be performed due to intra-abdominal dense adhesions. A total of 118 women were included in the study. BTL during $\mathrm{C}$-section was added to the operations of 51 patients (43\%) and $67(57 \%)$ patients did not want BTL (Figure 1). The number of the children at home, and number of prior $\mathrm{C}$-section were significantly higher in women who accepted BTL during $\mathrm{C}$-section compared to women who did not want BTL during C-section. The differences between the groups in terms of age, duration of marriage, gravida, education level, income status, gender of the children at home, and use of previous contraception were not statistically significant. Demographic characteristics are shown in table 1.

Reasons of patients who did not want BTL during C-section are shown in table 2. The most common reason for BTL at caesarean section in this study was religious beliefs $(n=18$, $26.8 \%$ ) followed by demand to use reversibl contraceptive method $(n=12,17.9 \%)$, partner who does not want BTL $(n=17.9,18 \%)$, desire to have children in the future $(n=9$, $13.4 \%)$, worries about the future $(n=7,10.9 \%)$, indesicion $(\mathrm{n}=6,8.9 \%)$, and fear of complications related to BTL $(\mathrm{n}=4$, $5.9 \%)$.

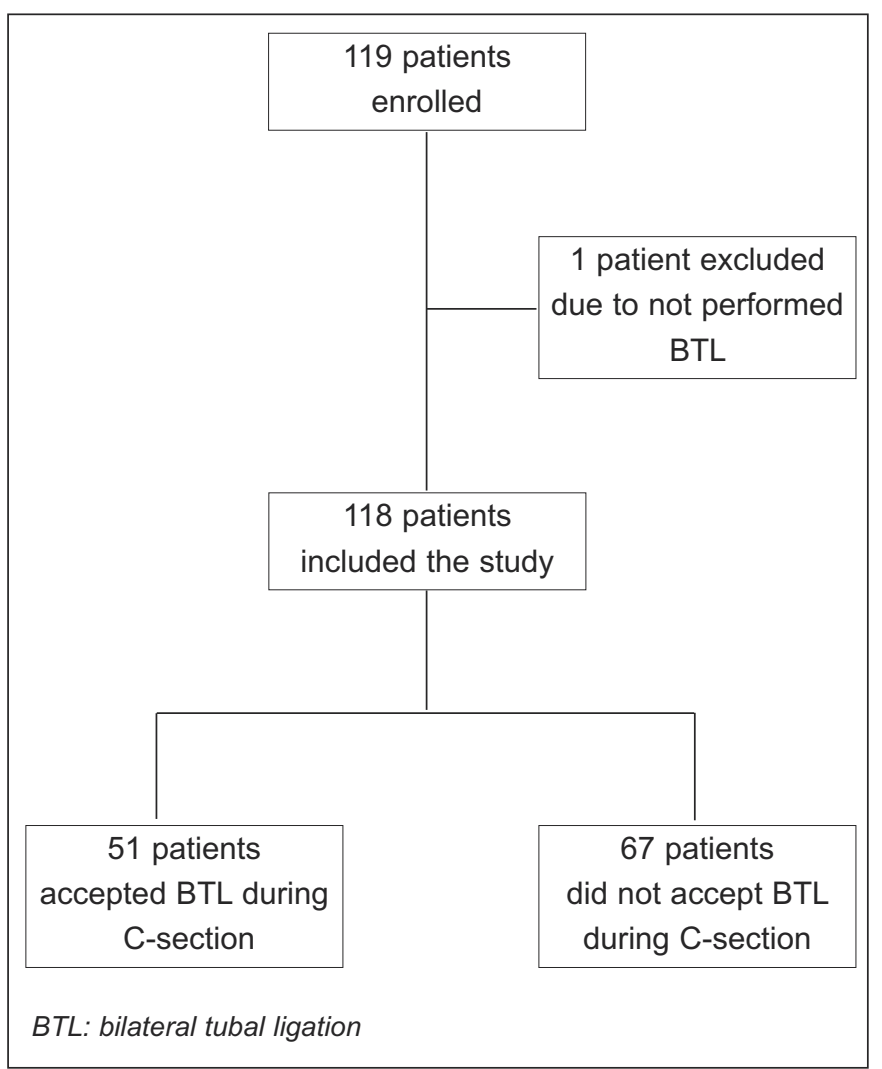

Figure 1: Flowchart of study profile. 
Table 1: Demographic and clinic characteristics of groups

\begin{tabular}{|c|c|c|c|}
\hline Variables & $\begin{array}{l}\text { BTL no } \\
67(56.77 \%)\end{array}$ & $\begin{array}{l}\text { BTL yes } \\
51(43.22 \%)\end{array}$ & $p^{\star *}$ \\
\hline $\operatorname{Age}^{*}(y)$ & $31.09 \pm 4.70$ & $32.11 \pm 4.41$ & 0.232 \\
\hline 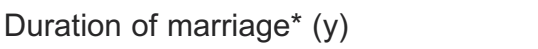 & $11 \pm 4$ & $11 \pm 4$ & 0.902 \\
\hline Gravida* & $3.8 \pm 1$ & $4 \pm 1$ & 0.427 \\
\hline Number of surviving children* & $2 \pm 0.5$ & $2.5 \pm 0.7$ & $<0.001^{* *}$ \\
\hline Number or prior C-section n (\%) & & & $0.001^{* *}$ \\
\hline 2 & $59(88 \%)$ & $30(58 \%)$ & \\
\hline$\geq 3$ & $8(11 \%)$ & $21(41 \%)$ & \\
\hline Education level n (\%) & & & 0.192 \\
\hline 1 & $48(71 \%)$ & $40(78)$ & \\
\hline 2 & $12(17 \%)$ & $10(11 \%)$ & \\
\hline 3 & $7(10 \%)$ & $1(2 \%)$ & \\
\hline Income status (monthly) n (\%) & & & $0.033^{* *}$ \\
\hline$<1000(\mathrm{tl})$ & $7(10 \%)$ & $1(2 \%)$ & \\
\hline $1000-2000(\mathrm{tl})$ & $29(43 \%)$ & $33(64 \%)$ & \\
\hline$\geq 2000(\mathrm{tl})$ & $31(46 \%)$ & $17(33 \%)$ & \\
\hline Gender of the children at home $n(\%)$ & & & 0.076 \\
\hline Only female & $24(35 \%)$ & $9(17 \%)$ & \\
\hline Only male & $15(22 \%)$ & $12(23 \%)$ & \\
\hline Both & $28(41 \%)$ & $30(58 \%)$ & \\
\hline Use of previous contraception $n(\%)$ & & & 0.095 \\
\hline Yes & $26(38 \%)$ & $28(54 \%)$ & \\
\hline No & $41(62 \%)$ & $23(45 \%)$ & \\
\hline
\end{tabular}

BTL: bilateral tubal ligation, *Variables are Mean $\pm S D .{ }^{* *} P<0.05$, significant. Education level; $1=<8$ years, $2=8-12$ years, $3=>12$ years

Table 2: Reasons for not wanting tubal ligation during C-section

\begin{tabular}{lcc}
\hline Causes & Number & Percentage \\
\hline Religious beliefs & 18 & 26.8 \\
Reversible contraceptive method demand & 12 & 17.9 \\
Partner who does not want tubal ligation & 12 & 17.9 \\
Incompleted family size & 9 & 13.4 \\
Worries about the future & 7 & 10.4 \\
Indesicion & 6 & 8.9 \\
Fear of complications related to tubal ligation & 4 & 5.9 \\
\hline
\end{tabular}

\section{Discussion}

In developing countries, there is a rapid population increase due to increased pregnancy rates, which leads to an increase in risky pregnancies. This will be solved by using of effective contraception methods. In developed and developing countries surgical sterilization is adopted widely. In United States, $38 \%$ of women with children undergo BTL. Postpartum BTL constitutes half of all sterilization procedures and it is higher in those who give birth with C-section compared to those who give vaginal birth. Every year about 340,000 Americans undergo sterilization surgeries and this constitutes $8-9 \%$ of all births (12).
Although there are many BTL methods in the literature, most frequent technique was described in 1929 by Pomeroy. These kinds of applications continued until 1960s and as of early 1970s surgical sterilization started to be used more commonly (13). In a lot of series, sterilization was shown to be safe and secure and rate of morbidity was reported to be between 1 to 6 percent (14).

In our study, it was shown that $43 \%$ of women with a history of least $2 \mathrm{C}$-sections wanted tubal sterilization during Csection. In another study, it was shown that previous $\mathrm{C}$-section history included $60 \%$ of BTL during C-section and half of the women did not have any underlying pathology (15). 
Socioeconomic status and history of C-section constitute the most important risk factors in requesting BTL during C-section (15). In a study conducted by Barros et al. it was detected that $9.4 \%$ of women were sterilized during $\mathrm{C}$-section and $31 \%$ of patients with a history of C-section underwent BTL procedure during their second $\mathrm{C}$-section. In the study, $3.7 \%$ of the patients who had C-section had low income while $20 \%$ of them had high income (16). Consistently, it was determined in our study that $2 \%$ of those who wanted BTL had low income. This ratio was statistically higher in patients who did not want BTL $(10 \%)$. This can be explained by young age of the patients ( $30 \%$ of patients under 30 years old) and by the fact that the gender of the children they have is only boy or only girl (8/9).

Age during BTL constitutes the most important risk factor for future regret. A systematic review analyzing the relation between regret after sterilization and the age during sterilization showed that women who were 30 years old or younger during sterilization had twice regret than those who were above 30 during sterilization. Moreover, it was shown that these patients had undergone 8 times more tubal recanalization operations or evaluations for in vitro fertilization (IVF) (17). In another study, main causes for regret after BTL were reported to be young age $(<25)$, inadequate awareness about the procedure and knowing fewer contraception methods before BTL (18). In our study, none of the patients who requested BTL was under 25 years, and $30 \%(15 / 51)$ of patients who requested the procedure were below 30 years old. Therefore, informed consent of the patient requires considerably more counseling to be provided by the physician regarding potential risks and benefits of this procedure than it is required for alternative methods of sterilization and contraception (19).

Tubal sterilization is often requested by women who are around the age of 30 and who have completed their family size. The mean age of women sterilized during C-section in this study was 32.1 years. This result was similar to those obtained in Spain and Nigeria $(11,13)$. The mean age for BTL is a little lower (26.6-32 years) in Asia, Latin America, Caribbean and North America than that of our report (20).

In developing countries, the age of women who undergo tubal sterilization ranges from 32 to 35 years old, after they have had 6-7 living children. In this study, it was found that the mean number of children living at home of women sterilized during $\mathrm{C}$-section to be 2.5. In a study conducted by Muhitir et al., the mean number of surviving children was found to be two children lower for women sterilized during $\mathrm{C}$ section (11). The risks and cost associated with repetitive operations may also result in the lower number of children by these women.

It is general practice to suggest sterilization to a woman following two or three $\mathrm{C}$-sections because of the hypothesis that there is a risk of operative complications and poor perinatal outcomes (21-23). The indications for BTL during C-sec- tion in this study were complications risks associated with repeated $\mathrm{C}$-sections and being reached the targeted number of children. The common reasons for BTL during C-section in this study were religious beliefs followed by demand to use reversibl contraceptive method, partner who does not want BTL and desire to have children in the future. In developing countries, use of BTL is limited due to religious restrictions, legal limitations, inadequate opportunities, requirement of operation and the fact that the method is irreversible (2-4). On the other hand, in United States, family planning policies and medical norms differ among states. For example, patients with public insurance in California have greater access to long-acting reversible methods that may constitute an alternative to sterilization (24).

\section{Conclusion}

As far as we know, this is the first study conducted in Turkey to analyze female sterilization by BTL during C-section in women with a history of repeated $\mathrm{C}$-section operations. We found that $43 \%$ of women who have given birth before 2 or more C-section want to have BTL for contraception during $\mathrm{C}$-section. In one fourth of the cases, pregnant women did not want BTL due to religious beliefs.

\section{: The authors reported no conflict of interest}

\section{References}

1. Patil E, Jensen JT. Permanent Contraception for Women. Semin Reprod Med. 2016;34(3):139-44

2. Adesiyun A. Female sterilisation by tubal ligation: A reappraisal of factors influencing decision making in a tropical setting. Arch Gynecol Obstet 2007;275(4):241-4.

3. Aisien AO, Oronsaye AU. Two decades of minilaparotomy female sterilization at the University of Benin Teaching Hospital. Niger Postgrad Med J 2007;14(1):67-71.

4. Pati S, Cullins V. Female sterilization. Evidence. Obstet Gynecol Clin North Am. 2000;27(4):859-99.

5. Mutihir JT, Aisien AO, Ujah IA. A review of bilateral tubal ligation at caesarean section in Jos, Nigeria. Niger Postgrad Med J 2007;14(3):253-5.

6. Perkins RB, Morgan JR, Awosogba TP, Ramanadhan S, Paasche-Orlow MK. Gynecologic Outcomes After Hysteroscopic and Laparoscopic Sterilization Procedures. Obstet Gynecol. 2016;128(4):843-52

7. Fernandez H, Legendre G, Blein C, Lamarsalle L, Panel P. Tubal sterilization: pregnancy rates after hysteroscopic versus laparoscopic sterilization in France, 2006-2010. Eur J Obstet Gynecol Reprod Biol. 2014;180:133-7.

8. Wilcox LS, Chu SY, Eaker ED, Zeger SL, Peterson HB. Risk factors for regret after tubal sterilization: 5 years of follow up in a prospective study. Fertil Steril 1991;55 (5):927-33 
9. Grubb GS, Peterson HB, Layde PM, Rubin GL. Regret after decision to have a tubal sterilization. Fert Steril 1985;44(2):246-53.

10. S Dubey, SK Singh. Sociocultural analysis of the cases of reversal of female sterilization: A retrospective study. Health and Population Perspectives and issues.1992; 15(1-2): 26-31

11. Mutihir JT, Aisien AO, Ujah IA. A review of bilateral tubal ligation at caesarean section in Jos, Nigeria. Niger Postgrad Med J 2007;14(3):252-5

12. Potter JE, Stevenson AJ, White K, Hopkins K, Grossman D. Hospital Variation in Postpartum Tubal Sterilization Rates in California and Texas. Obstet Gynecol. 2013;121(1): 152-8

13. Moreno JM, Bartual E, Carmona M, Araico F, Miranda JA, Herruzo AJ. Changes in the rate of tubal ligation done after cesarean section. Eur J Obstet Gynecol Reprod Biol. 2001; 97(2):147-51.

14. Gizzo S, Bertocco A, Saccardi C, Di Gangi S, Litta PS, D'antona D, et al. Female sterilization: update on clinical efficacy, side effects and contraindications. Minim Invasive Ther Allied Technol. 2014;23(5):261-70

15. Moreno JM, Bartual E, Carmona M, Araico F, Miranda JA, Herruzo AJ. Changes in the rate of tubal ligation done after cesarean section. Eur J Obstet Gynecol Reprod Biol. 2001;97(2):147-51.

16. Barros FC, Vaughan JP, Victora CG, Huttly SR Epidemic of caesarean sections in Brazil. Lancet. 1991;338(8760): 167-9.

17. Curtis KM, Hohllajee AP, Peterson HB. Regret following female sterilization at a young age: a systematic review. Contraception. 2006;73(2): 205-10

18. Hardy E, Bahamondes L, Osis MJ, Costa RG, Faúndes A. Risk factors for tubal sterilization regret, detectable before surgery. Contraception 1996;54(3):159-62.

19. ACOG committee opinion. Tubal ligation with cesarean delivery. Number 205, August 1998. Committee on Coding and Nomenclature. American College of Obstetricians and Gynecologists.Int J Gynaecol Obstet. 1998;63(3):311

20. Rutenberg N, Landry EA. Comparison of sterilization use and demand from the demographic and health surveys. Int Fam Plann Perspect 1993;19(1):4-13.

21. Abenhaim HA, Benjamin A, Koby RD, Kinch RA, Kramer MS. Comparison of obstetric outcomes between on-call and patients' own obstetricians. CMAJ 2007;177 (4):352-6

22. Gedikbasi A, Akyol A, Bingol B, Cakmak D, Sargin A, Uncu R, et al. Multiple repeated cesarean deliveries: operative complications in the fourth and fifth surgeries in urgent and elective cases. Taiwan J Obstet Gynecol. 2010;49 (4):425-31

23. Yücel B, Kadiroğulları P, Karaaslan O, Aydın T, Seçkin KD, Gedikbaşı A. Four or More Cesarean Sections, is it Still Safe? Gynecol Obstet Reprod Med 2017; Mar 28. DOI: http://dx.doi.org/10.21613/GORM.2017.677 [Epub ahead of print]

24. Harper CC, Blum M, Bocanegra HT, Darney PD, Speidel JJ, Policar M, et al. Challenge in translating evidence into practice: the provision of intrauterine contraception. Obstet Gynecol. 2008; 111(6):1359-69 